\title{
Coulisses
}

Revue de théâtre

10 | Printemps 1994

Varia

\section{Chemins de croix}

\section{(2) OpenEdition}

1 Journals

Édition électronique

URL : http://journals.openedition.org/coulisses/3131

DOI : 10.4000/coulisses.3131

ISSN : 2546-9460

\section{Éditeur}

Presses universitaires de Franche-Comté

\section{Édition imprimée}

Date de publication : 1 juin 1994

Pagination : 80

ISSN : 1150-594X

\section{Référence électronique}

"Chemins de croix », Coulisses [En ligne], 10 | Printemps 1994, mis en ligne le 15 mars 2019, consulté le 31 octobre 2019. URL : http://journals.openedition.org/coulisses/3131 ; DOI : 10.4000/coulisses.3131

Ce document a été généré automatiquement le 31 octobre 2019

Coulisses 


\title{
Chemins de croix
}

\author{
Chemins de croix \\ de Kangni Alemdjrodo par le groupe de Montbéliard. \\ Mise en scène : Marcel Djondo \\ PREMIERE : Le samedi 21 mai à 20h30 Théâtre Municipal de Montbéliard.
}

NB : Un car est prévu pour aller à Montbéliard. Si vous êtes intéressé(e)s, contactez le T.U.F.C. au 81-66-53-47.

\section{Le TUFC à Montbéliard}

1 En Octobre 1993, le TUFC a délocalisé ses activités à Montbéliard avec le concours du Centre d'Art et Plaisanterie.

L'animateur-metteur en scène Marcel DJONDO est à la fois étudiant en LEA et comédienanimateur au Centre d'Art et Plaisanterie. Sous son impulsion se sont mis en place deux ateliers, l'un axé sur «le théâtre d'intervention », l'autre sur la création de CHEMINS DE CROIX. Le dossier présenté a été retenu pour la présélection du deuxième festival de Théâtre Universitaire organisé par le Théâtre Nanterre-Amandiers.

Le groupe témoigne de la variété des études supérieures sur l'aire urbaine BelfortMontbéliard: IUFM, LEA, AES, SVST et des origines diverses des étudiants qui les poursuivent. Français, togolais, kurde, algérien répètent inlassablement pour le plaisir d'être ensemble, de créer un lien avec le public, de dire à leur manière ce qui leur tient à cœur, de briser le mur du silence.

\section{L'auteur}

2 Né en 1966 à Lomé (Togo), Kangni ALEMDJRoDo, titulaire d'un DEA de Lettres modernes de l'Université de Bordeaux est à la fois comédien, metteur en scène et écrivain. Il a écrit des nouvelles, Un parfum de grenades lacrymogènes (in REVUE NOIRE $n^{\circ} 5$ ), La gazelle s'agenouille pour pleurer (Editions Canevas, Bruxelles 1993), et prépare actuellement un roman L'invention de la tribu.

Son œuvre dramatique lui a valu d'être boursier de la Fondation Beaumarchais en 1993 pour une résidence d'écriture au Festival International des Francophonies de Limoges. 
En effet, La saga des rois a remporté un franc succès et Chemins de croix obtenu en 1990 le prix Tchicaya U'Tamsi du concours Théâtral Interafricain.

\section{La pièce}

3 Une prison, deux jeunes détenus, Amel et Amouro, un gardien, l'Aumônier. Pourquoi sont-ils là ? Ils ont été arrêtés pour avoir participé à une grève d'étudiants. Pourquoi se sont-ils engagés dans cette manifestation ? Conviction ? Hasard ? Quelle peine les attend ? Quel sera leur avenir ? Que va devenir la femme aimée ? Lucette, le gardien Cassecouilles et l'Aumônier leur proposent des solutions. Y céderont-ils ? Sur un fond de guerre, de crise sociale, Amouro s'interroge sur l'existence. Lui répond le solide bon sens du gardien Cassecouilles. «ça sert à quoi la grève ? „... Mais aussi : «Le silence c'est le bonheur... »

4 Dans cette opposition, c'est l'Ecrivain et le bulletin d'informations radiodiffusées qui ont le dernier mot. 